\title{
ACTIVE WAITING: AN INVESTIGATION OF DELAYED WINBACK STRATEGIES
}

\author{
Mark P. Leach, Loyola Marymount University, USA \\ Annie H. Liu, Victoria University of Wellington, New Zealand \\ Sijun Wang, Loyola Marymount University, USA
}

\begin{abstract}
Regardless of how effective a company's sales process or CRM program is, inevitably, some customers will defect and switch to alternative suppliers. When customers defect, it typically is not a rash decision, but the result of a well thought out evaluation. Thus, effective reacquisition strategies are likely to involve an assessment of buying decision cycles and current relations with buying center members (some of which may have recently turned sour). Thereby, the best course of action may include simply letting some time transpire; sales organizations may find that active waiting can facilitate a stronger winback position at some future time. Using critical incident techniques (CIT), this study qualitatively examines the reacquisition strategies of fifty industrial salespeople and specifically attempts to understand why salespeople strategically decide to wait as part of their comprehensive win-back strategy for lost customers. Interviews from salespeople who utilized a delay strategy suggest that this does not mean that the customer is ignored. Instead, thoughtful and consistent contact facilitates and lays the groundwork for future reacquisition efforts. When a delay strategy is required or chosen, our findings suggest that it is due to one or a combination of five reasons: (1) allow customer time to "cool down", (2) allow customer to change personnel or buying influence in the buying center, (3) allow time for the replacement supplier to falter, (4) dedicate time and efforts to coordinate with the customer's buying cycle, (5) actively improve capabilities and/or implement personnel change in the sales organization.
\end{abstract}

Contributing to the relationship marketing and sales literature, this study is one of the first to empirically investigate delayed strategies to regain valuable lost customers. The findings from our in-depth interviews afford insights to help sales executives to: (1) better understand customers' capacity and internal process for switching back, (2) develop effective buyer-seller relationship and support strategies to regain profitable business, and (3) allow sales organizations the discernments and patience to actively wait for the best time to regain lost customers.

References available upon request 